\title{
Impact of probability distribution on the uncertainty of resistance measurement
}

\author{
Stanisław Szczesny ${ }^{1 *}$, Anna Golijanek-Jędrzejczyk ${ }^{1}$, Dariusz Świsulski ${ }^{1}$ \\ ${ }^{1}$ Gdańsk University of Technology, 80-233 Gdańsk, Poland
}

\begin{abstract}
The paper presents studies on the influence of probability distributions on the expanded uncertainty of the resistance measurement. Choosing the correct probability distribution is very important to estimate of measurement uncertainty. The paper presents the results of analysis of the resistance measurement uncertainty using the technical method of resistance: $100 \mathrm{G} \Omega$. The analysis of the uncertainty measurement of resistance was carried out repeatedly, each time assuming a different probability distribution of measuring instruments (normal, quadratic, $U$ and triangular distribution). The results of the research presented in the article show that the influence of the assumed probability distributions on the result of the measurement uncertainty analysis is significant and results discrepancies can reach up to $40 \%$.
\end{abstract}

\section{Introduction}

Understanding the fundamentals of the uncertainty theory is important because measurement uncertainty is a component of the presented measurement result. It is crucial not only to carry out the given experiment, but also to correctly present the obtained value of the measured value together with the qualitative measure measurement uncertainty, because only complete results can be compared with each other.

This paper is a continuation of research conducted by the authors on the influence of wrongly assumed probability distribution on the uncertainty of resistance measurement by technical method [1].

\section{Measurement method}

Extended uncertainty of resistance measurement by technical method $U_{p}(R)$ is determined in accordance with the guidelines presented in the GUM guide [2]. In order to estimate it, the coverage factor $k_{p}$ should be determined for the assumed probability of expansion and the uncertainty of the measurement $u_{c}(R)$.

$$
U_{p}(R)=k_{p} \cdot u_{c}(R)
$$

Combined uncertainty of resistance measurement $u_{c}(R)$, assuming no correlation between the uncertainties of the input quantities, according to the law of uncertainty propagation, specifies the following formula:

$$
\begin{aligned}
u_{c}(R) & =\sqrt{\left(c_{1}\right)^{2} \cdot u^{2}(U)+\left(c_{2}\right)^{2} \cdot u^{2}(I)}= \\
& =\sqrt{\left(\frac{\partial f(U, I)}{\partial U}\right)^{2} \cdot u^{2}(U)+\left(\frac{\partial f(U, I)}{\partial I}\right)^{2} \cdot u^{2}(I)}= \\
& =\sqrt{\left(\frac{1}{I}\right)^{2} \cdot u^{2}(U)+\left(\frac{-U}{I^{2}}\right)^{2} \cdot u^{2}(I)}
\end{aligned}
$$

\footnotetext{
*Corresponding author: stanislaw.szczesny@pg.edu.pl
}

where: $c_{l}, c_{2}$ - sensitivity coefficients determined on the basis of partial derivatives of the measurement function $f(U, I)$ (Ohm's law), $u(U)$ - uncertainty of voltage measurement $U, u(I)$ - uncertainty of current measurement $I$.

Uncertainty of voltage $u(U)$ and current $u(I)$ measurement were determined using the type A and type $B$ methods [3].

Uncertainty type B is estimated on the basis of known or assumed probability density function measurements, which require the observer to have knowledge of the instruments that were used in the experiment. The main problem in estimating type B $u_{B}(x)$ uncertainty is the selection of the probability density function. There are many possibilities, in the studies limited to four: normal, quadratic, $U$ and triangular distribution [4]. The value of the maximum permissible error is variously characterized depending on whether the value is measured by an analogue or digital meter. It is determined on the basis of parameters defined by the manufacturer of the measuring device [3].

\section{Experimental research}

The test object was a $100 \mathrm{G} \Omega$ reference resistor. Basic parameters of this object was presented in the Table 1 .

Table 1. Parameters of the reference resistor [5].

\begin{tabular}{|l|c|c|}
\hline 1 & Resistance & $100 \mathrm{G} \Omega$ \\
\hline 2 & Class & 2.5 \\
\hline 3 & Voltage & $5 \mathrm{kV}$ \\
\hline 4 & Current & $50 \mathrm{nA}$ \\
\hline 5 & Power & $0.25 \mathrm{~mW}$ \\
\hline
\end{tabular}


This resistor was measured by a Megger S1-568 (basic parameters of the meter are presented in Table 2).

Table 2. Parameters of the used measuring instruments [5].

\begin{tabular}{|c|c|c|}
\hline & Parameter & Megger S1-568 \\
\hline 1 & Current measurement range & $0.01 \mathrm{nA}-6 \mathrm{~mA}$ \\
\hline 2 & $\begin{array}{c}\text { Accuracy of current } \\
\text { measurement }\end{array}$ & $5 \% \pm 0.2 \mathrm{nA}$ \\
\hline 3 & Voltage measurement range & $30 \mathrm{~V}-5 \mathrm{kV}$ \\
\hline 4 & $\begin{array}{c}\text { Accuracy of voltage } \\
\text { measurement }\end{array}$ & $3 \% \pm 3 \mathrm{~V}$ \\
\hline 5 & Measuring voltage & $3 \mathrm{kV}$ \\
\hline
\end{tabular}

Resistance measurement was performed at $3 \mathrm{kV}$ test voltage generated by the meter. Each measurement was performed after two minutes from application of the test voltage to the resistor, then the voltage was disconnected for $30 \mathrm{~s}$ and this procedure was repeated 50 times.

In order to investigate the impact of an wrongly chosen probability distribution on the uncertainty of resistance measurement using the Megger S1-568 instrument, it is necessary to know the actual distribution of the measurement error of this meter. For this purpose, a series of measurements was carried out with this device, which showed that the probability distribution of voltage and current measurements, in practically every case, is a triangular [1].

\section{Estimating uncertainty of resistance measurement}

After importing the measurement data from the Excel spreadsheet to the advanced version of the R-Tech application [1], the uncertainty of the measurement was analysed. The experiment was repeated, changing the adopted probability distributions of measuring instruments.

When analysing the uncertainty of resistance measurements of $100 \mathrm{G} \Omega$, the voltage sensitivity factor is 15 orders of magnitude smaller than the current sensitivity coefficient. For this reason, the participation of combined standard uncertainty of voltage is close to zero. Therefore, special attention should be paid to the selection of a current measuring instrument, because the parameters of this device have a great impact on the result of the measurement uncertainty analysis.

Figures 1 present the combined standard uncertainty of resistance measurement depending on the selected probability distribution of measuring instruments.

On the basis of the presented data, it can be noticed that the highest uncertainty values are obtained for a $U$ distribution, and the smallest for a triangular one. As shown in Figure 1, assuming a $U$ distribution for the ammeter, the effect of the voltmeter distribution is imperceptible. The smallest uncertainty of measurement is obtained assuming a triangular current probability distribution. These discrepancies reach $40 \%$.

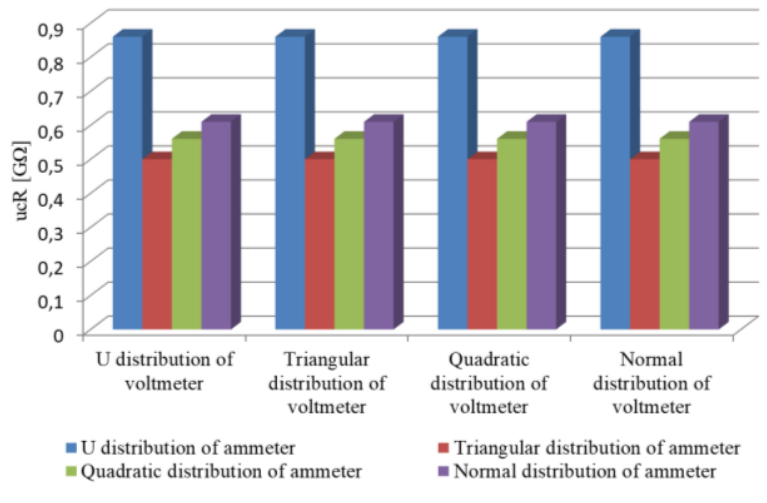

Fig. 1. Combined standard uncertainty of the resistance measurement depending on the selected probability distribution when testing the resistor $100 \mathrm{G} \Omega$.

If during resistance measurement $100 \mathrm{G} \Omega$ (using the Megger S1-568) instead of the triangular distribution the quadratic, normal or $U$ distribution would be chosen, the discrepancies in the estimated expanded uncertainty $U_{p}(R)$ would be $12 \%, 22 \%$ and $72 \%$, respectively.

\section{Summary}

In the cases analysed in the paper, the largest values of the combined standard uncertainty of a resistance measurement were obtained by choosing a $U$ distribution. In order to reliably evaluate the uncertainty of measurement, it is necessary to get to know the measuring instrument first. Based on the historical results obtained with this device, the probability distribution can be appropriately assumed to estimate the type B uncertainty.

Summarizing, it is important to correctly recognize and select the correct probability distribution of the measurement results of the measuring instrument used to measure the resistance. Only this approach guarantees obtaining the correct uncertainty of the measurement.

\section{References}

1. S. Szczesny, A. Golijanek-Jędrzejczyk, D. Świsulski, Influence of wrongly assumed probability distribution on the uncertainty of resistance measurement by technical method, Poznan University of Technology Academic Journals. Electrical Engineering, 100 (2019)

2. Guide to the Expression of Uncertainty in Measurement (GUM). ISO/IEC/OIML/BIPM, BIPM JCGM 100, (2008)

3. S. Szczesny, A. Golijanek-Jędrzejczyk, D. Świsulski, Zastosowanie aplikacji R-Tech do wyznaczania niepewności pomiaru rezystancji metoda techniczna. Zeszyty Naukowe Wydziału Elektrotechniki i Automatyki Politechniki Gdańskiej, 51, (2016)

4. H. Castrup, Distributions for Uncertainty Analysis, (2002)

5. Datasheets of resistor RN-1 and meter Megger S1568 